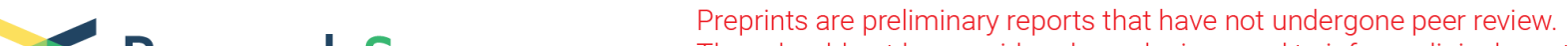 Research Square They should not be considered conclusive, used to inform clinical practice, or referenced by the media as validated information.
}

\section{A systematic review of human giardiasis in Bangladesh: public health perspective}

Biplob Hossain ( $\nabla$ bhossain@icddrb.org )

icddr,b https://orcid.org/0000-0002-4934-9866

\section{Humaira Rashid}

International Centre for Diarrhoeal Disease Research Bangladesh

\section{Zannatun Noor}

International Centre for Diarrhoeal Disease Research Bangladesh

\section{Mamun Kabir}

International Centre for Diarrhoeal Disease Research Bangladesh

\section{Sohag Miah}

Shahjalal University of Science and Technology

\section{Abdullah Siddique}

International Centre for Diarrhoeal Disease Research Bangladesh

\section{Rashidul Haque}

International Centre for Diarrhoeal Disease Research Bangladesh

\section{Research article}

Keywords: Giardiasis, Bangladesh, child growth, intestinal permeability, diarrhea, review

Posted Date: March 13th, 2020

DOI: https://doi.org/10.21203/rs.3.rs-17054/v1

License: (c) (1) This work is licensed under a Creative Commons Attribution 4.0 International License.

Read Full License 


\section{Abstract}

Background: Giardiasis identified as a leading cause of gastrointestinal pathogen in young children worldwide, is also common in Bangladesh. There has been an emerging evidence of an association between giardiasis and child growth. This systematic review focuses only on Bangladeshi children. Prevalence of giardiasis with its adverse health effects and the advancement of diagnosis has been reviewed.

Methods: A broad review of literature, electronic databases, and books within the time frame of 1970 and 2019 has been searched. Data published on giardiasis prevalence, outcomes (child growth, intestinal permeability, and diarrhea) and advances of diagnosis in Bangladesh has been searched.

Results: Both assemblages A and B genotypes of Giardia lamblia are responsible for human giardiasis in Bangladesh. Recent studies on Bangladeshi children suggested Giardia species infections has an adverse impact on poor child growth which have further characterized associations with altered gut epithelial barrier dysfunction, as well as diarrhea. Indeed emerging evidence indicates the key consequence of Giardia colonization is nutrient malabsorption.

Conclusions: In Bangladesh giardiasis remains a major public health concern, especially in children age $<5$ years but is considered as a neglected disease. In order to reduce the burden of giardiasis in developing countries such as Bangladesh, more focus is require to include this disease in public health policies.

\section{Background}

Giardiasis, one of the most frequent flagellated protozoan parasitic infection caused by Giardia lamblia (Giardia duodenalis and Giardia intestinalis), is considered to be a worldwide neglected disease (1). Giardiasis is more prevalent in children living in low hygiene settings with poor quality of water and overcrowding (2). In high-income countries, the prevalence of giardiasis in humans is low (1-7\%), whereas in low-income countries it is highly prevalent $(4-43 \%)(3,4)$. It is one of the most common pathogens that causes diarrhea in people among developed and developing countries. The lifecycle of Giardia consists of two stages, trophozoites and infectious cysts. Transmission of giardiasis concede by the ingestion of infectious cysts, where 10 cysts is sufficient to acquire the illness. Clinical giardiasis causes vomiting, flatulence, abdominal pain, bloating and loss of weight following malabsorption $(5,6)$. Evaluation of Giardia contaminations that's asymptomatic, but it has the ability for the Giardia cyst transmission, differs from 5 to 15\% (7). In Asia, Africa, and Latin America, 500,000 new cases of giardiasis are reported each year (8). Giardia infection prevalence rate less than $1 \%$ is intermittent, $1-10 \%$ is endemic and more than $10 \%$ is hyperendemic. According to the guidelines of the World Health Organization (WHO) there is sixteen endemic and four hyperendemic areas (9).

Giardia spp. can cause both acute and chronic diarrhea and can be presented as an asymptomatic infection (10) which leading to weight loss due to nutrients malabsorption (11). During acute Giardia 
infection with diarrhea abdominal pain and the clinical manifestations of malabsorption are anticipate (12). On the other hand, chronic infection is associated with poor cognitive function as well as malnutrition and deficiencies in micronutrients including vitamin $A$, iron and anemia $(10,13,14)$. The combination of these problems has an immense impact causing underweight and stunting in children. Although Bangladesh has made sustainable progress over the past few years, $(15,16)$ but we need to reduce the proportion of underweight children among under-5 children from $32.6-20 \%$ and stunting $36.1-25 \%$ to achieved sustainable development goals.

This is the first systematic review on possible health issues of giardiasis in Bangladesh. We investigated articles that published in 1970 to 2019 which convey giardiasis as a major public health concern in Bangladesh, especially in young children aged $<5$ years old. This review specifically identified the prevalence rate, child growth status and diagnosis of giardiasis in Bangladesh, the most frequently found assemblages in humans giardiasis and it's adverse health outcomes.

\section{Methods}

This systematic review was conducted according to the Preferred Reporting Items for Systematic Reviews and Meta-Analyses (PRISMA). Several international journal databases and Bangladeshi journals were searched from 1970 to 2019 which have been published in English. International databases include Web of Science, PubMed, PLOS One, journal of Clinical Infectious Diseases (CID), American Journal of Tropical Medicine and Hygiene (AJTMH), Google Scholar along with Bangladeshi databases such as Bangladesh Journal of Scientific Research (BJSR), Dhaka University Journal of Biological Science (DUJBS), Bangladesh Journal of Zoology (BJZ) and Bangladesh Medical Research Council (BMRC) and others has been searched. This review identified research studies related to Giardia infection and its adverse health effects across Bangladeshi population using keywords such as "Giardiasis", "Giardia infection", "Human", "Adverse effects/disorder", "Bangladesh".

In this review we excluded articles that did not had proper information. And the articles were also omitted that had only information related to experimental method, molecular and biochemical analysis of Giardia. In fact, papers were also removed from the consideration without full text access after searching in other databases. The last date searched was November 30th, 2019.

\section{Results}

\section{Description of the studies identified:}

We found 187 titles on the initial search, of which only 17 met the inclusion criteria and were finally included for this systematic review. Figure 1 shows the way to get the articles used in this review according to PRISMA. Thus, in this review we included possible health risk of giardiasis from 17 articles.

\section{Epidemiology:}


Giardia infection occurs worldwide (17) with the highest burden of giardiasis borne by people living in developing countries, particularly the tropics and subtropics, where hygiene and sanitation are inadequate like Bangladesh. Giardiasis was estimated to be as high as 20 to $40 \%$ in resource-limited settings with the highest infection rate among children under the age of 5 (18). Diarrhea associated with intestinal protozoal parasites such as Giardia, Entamoeba and Cryptosporidium has been one of the main reasons of child mortality in developing countries in sub-Saharan Africa and South Asia, including Bangladesh $(19,20)$.

In low and middle-income countries (LMIC) such as Bangladesh, the exact burden of giardiasis is difficult to quantify as the reports can vary by geographic region, study design, sample size, incubation, severity of symptoms, and the sensitivity of the diagnostic method.

In a large case-control study conducted on 2534 patients in Bangladesh, association between infection with $G$. lamblia genotypes assemblage $A$ and assemblage $B$ were tested, where significant odds ratio for diarrhea was observed for assemblage $A$ infections whereas assemblage $B$ infection was associated with asymptomatic Giardia infection (21). In another study performed in an urban slum of Dhaka, Bangladesh, shown $31.1 \%$ of children had at least one episode of Giardia lamblia diarrheal infection in first 2 years of age (22).

\section{Pathogenesis of Giardia spp.:}

Pathogenesis and host response of Giardia infection are not fully understood. Following the swallow of Giardia cysts from contaminated food, water or interaction with infected human or animal excystation occurs in the human intestine, which released two to four trophozoites. Troprozoites are attached to the epithelial surface of the intestine through ventral adhesive disk. Consequently, diarrhea occurs in response to this tight attachment. (See Fig. 2)

This pathophysiological process leads to Enterocyte apoptosis, intestinal barrier failure, activation of host lymphocytes and villous atrophy. As a results disaccharides deficiencies, small bowel malabsorption, hypersecretion of anions, and increased rates of intestinal transit occurs into the human body (23-31).

\section{Giardiasis And Poor Child Growth:}

Associations between Giardia infection and child growth impairments varied by study, population and location, but children in Bangladesh are consistently associated with poor child growth with Giardia infection burdens (Table 1).

Giardia had a considerable negative correlation with linear growth in a cohort study of malnutrition and enteric disease (MAL-ED), which lasted for the first 2 years of life up to 5 years in some cases. Giardia infection was associated with smaller reductions in the length-for-age $z$ score (LAZ) in quantity instead of prevalence using the exposure criterion (32). In another case-control study on Bangladeshi children 
showed that Giardia infection was significantly related to undernourished cases after age, sex, and diarrhea were modified and further adjusted to sociodemographic factors (33). Similarly, from a prospective birth cohort study in Dhaka, $7 \%$ of children were Giardia positive (stool specimen) with a decreased LAZ score in the first 6 months of life as an early life risk factor (34). Moreover, infection with Giardia before 6 months of age was associated with a decrease in LAZ - 0.29 (95 percent $\mathrm{Cl},-0.64$ to 0.07 ) and a decrease in weight-for-age $z$ score (WAZ) at 24 months of age -0.29 (95 percent $\mathrm{Cl},-0.53$ to - 0.05) indicating a stunted growth rate (35). In addition, evidence of elevated Giardia-specific IgM titre (GSIgM) was found in a longitudinal study of 298 rural Bangladeshi infants associated with poor WAZ and weight-for-height $z$ score (WHZ) ( $P=0.015$ and 0.039 respectively) (36). This findings suggest that infection with Giardia could be a potential obstacle to poor child growth up to 2 years of life and a crucial window of childhood vulnerability that is rarely recorded in a focused manner. 
Table 1

Health effects of giardiasis found in Bangladeshi children

\begin{tabular}{|c|c|c|c|c|c|}
\hline $\begin{array}{l}\text { Authors } \\
\text { Name }\end{array}$ & $\begin{array}{l}\text { Sample } \\
\text { Size }\end{array}$ & Age & Prevalence rate & Effects & $\begin{array}{l}\text { Reference } \\
\text { no. }\end{array}$ \\
\hline $\begin{array}{l}\text { Rogawsk } \\
\text { ET et al., } \\
2018\end{array}$ & 923 & $\begin{array}{l}0- \\
2 \text { years }\end{array}$ & $21.4 \%$ & Poor linear growth & (32) \\
\hline $\begin{array}{l}\text { Fahim } \\
\text { SM et al., } \\
2108\end{array}$ & 265 & $\begin{array}{l}0- \\
2 \text { years }\end{array}$ & $\begin{array}{l}14.6 \% \text { at } 7 \text { months of } \\
\text { age. } \\
8.2 \% \text { at } 15 \text { months of } \\
\text { age. } \\
1.6 \% \text { at } 24 \text { months of } \\
\text { age. }\end{array}$ & $\begin{array}{l}\text { Intestinal inflammation } \\
\text { and increased intestinal } \\
\text { permeability }\end{array}$ & (37) \\
\hline $\begin{array}{l}\text { Rogawsk } \\
\text { ET et al., } \\
2017\end{array}$ & 2089 & $\begin{array}{l}0- \\
2 \text { years }\end{array}$ & $13.6 \%$ & $\begin{array}{l}\text { Persistent infections } \\
\text { contribute to intestinal } \\
\text { permeability and stunted } \\
\text { growth }\end{array}$ & (35) \\
\hline $\begin{array}{l}\text { Platts- } \\
\text { Mills JA } \\
\text { et } \\
\text { al.,2017 }\end{array}$ & 964 & $\begin{array}{l}6-23 \\
\text { months }\end{array}$ & $\begin{array}{l}\text { Case: } 22.4 \% \text { and } \\
\text { Control: } 12.4 \%\end{array}$ & $\begin{array}{l}\text { Associated with } \\
\text { malnutrition }\end{array}$ & (33) \\
\hline $\begin{array}{l}\text { Donowitz } \\
\text { JR et } \\
\text { al.,2016 }\end{array}$ & 629 & $\begin{array}{l}0- \\
2 \text { years }\end{array}$ & $\begin{array}{l}7 \% \text { at } 6 \text { months of age } \\
\text { and } 74 \% \text { of cohort } \\
\text { stool }\end{array}$ & $\begin{array}{l}\text { Risk factor for stunting at } \\
\text { age } 2\end{array}$ & (34) \\
\hline $\begin{array}{l}\text { Mondal } \\
\text { D et } \\
\text { al.,2011 }\end{array}$ & 147 & $\begin{array}{l}0-12 \\
\text { months }\end{array}$ & $34 \%$ & $\begin{array}{l}\text { Defect in mucosal } \\
\text { immunity }\end{array}$ & (38) \\
\hline $\begin{array}{l}\text { Mondal } \\
\text { D et } \\
\text { al.,2009 }\end{array}$ & 289 & $\begin{array}{l}2- \\
5 \text { years }\end{array}$ & -- & No significant association & (39) \\
\hline $\begin{array}{l}\text { Lutfun } \\
\text { Nahar et } \\
\text { al., } 1999\end{array}$ & 198 & $\begin{array}{l}6-59 \\
\text { months }\end{array}$ & $\begin{array}{l}31 \% \text { single infection, } \\
7.7 \% \text { double infection } \\
\text { and } 2.8 \% \text { triple } \\
\text { infection }\end{array}$ & $\begin{array}{l}\text { Association with } \\
\text { malnutrition }\end{array}$ & $(40)$ \\
\hline $\begin{array}{l}\text { Goto R et } \\
\text { al., } 2008\end{array}$ & 298 & $\begin{array}{l}3-15 \\
\text { months }\end{array}$ & $1 \%$ & $\begin{array}{l}\text { Elevated GSIgM } \\
\text { associated with poor WAZ } \\
\text { and WHZ }\end{array}$ & (36) \\
\hline
\end{tabular}

\section{Giardiasis And Intestinal Permeability:}

Infection with Giardia has been correlated with altered human bowel architecture and experimental models $(28,41,42)$. In this regard, Bartelt et al. identified Giardia as a "stunting" pathogen (42) resulting in malabsorption of glucose, sodium and water in the body and decreased production of disaccharides 
(43-48). In MAL-ED study, Giardia infection was associated with high level of lactulose: mannitol (L: M) ratio, indicate of increased gut permeability. A similar study in rural area of Bangladesh reported that burden of giardiasis prevalence was correlated with greater level of intestinal permeability (49). Similarly, Goto et al. found that intestinal permeability function is impaired by elevated acid glycoprotein (AGP) as an indication of routine re-infection in rural Bangladeshi children along with elevated Giardia IgM titers (36).

Additionally an observational study of Bangladeshi infants of an urban area indicated giardiasis was associated with the intestinal barrier disruption (38). Furthermore, another prospective longitudinal study confirmed that giardiasis was significantly associated with concentrations of fecal myeloperoxidase (MPO) and alpha-1-anti-trypsin (AAT) in children under the age of 2 and was also significantly associated with score of environmental enteric dysfunction (EED) (37). Most of these studies showed evidence that giardiasis was associated with intestinal permeability. Improvements in analytical techniques have allowed the identification of Giardia in human samples associated with intestinal permeability. Study in Bangladesh to date has clearly demonstrated the relationship between human Giardia infection and abnormal gut permeability.

\section{Human Giardiasis Associated Diarrhea:}

According to the new Global Burden of Disease Survey, approximately 2.39 billion cases of diarrhea occurred worldwide and approximately 0.53 million children under five years of age died each year (19, 50). Diarrheal diseases are still very common among children under 5 years old in Bangladesh (51). In Bangladesh, Haque et al. reported intestinal protozoal parasites are significantly associated with diarrheal diseases, especially Giardia, Entamoeba and cryptosporidium (20). Several studies conducted in Bangladesh using diarrheal stools also found that Giardia spp. are responsible for diarrheal diseases (52-54). From May 2004 to April 2006, Haque et al. conducted a prospective case control study at the Dhaka hospital of the International Centre for Diarrheal Disease Research, Bangladesh (icddr,b) found that in case patients with diarrhea G. lamblia assemblage A was more prevalent than in healthy control subjects $(20 \%$ vs. $5 \%$; $<$ < 0.001$)(20)$. Another, Haque et al. study reported $11 \%$ pre-school children were infected with Giardia lamblia which one is second highest after Shigella flexneri (11.6\%) in diarrheal stool (55). Table 2 shows the prevalence rate of giardiasis in diarrheal stool by different test methods. 
Table 2

Prevalence of Giardia spp. infection in diarrheal stool in Bangladesh

\begin{tabular}{|lllll|}
\hline Authors Name & Sample Size & Age & Prevalence rate & Test Method \\
\hline Haque et al., 2005 & 1305 & All ages & $7.7 \%$ & EIA \\
\hline Suman et al,2011 & 266 & $<5$ years & $3.8 \%$ & EIA \\
\hline Kabir et al.,2018 & 832 & $<2$ years & $31.1 \%$ & TaqMan Array Card Assay \\
\hline Alam et al.,2011 & 77 & All ages & $79.22 \%$ & EIA \\
\hline Haque et al.,2003 & 289 & $2-5$ years & $11 \%$ & Microscopy \\
\hline
\end{tabular}

\section{Advances In The Diagnosis Of Giardiasis:}

Current Giardiasis diagnostic methods in Bangladesh include microscopic identification of Giardia cyst and tropozoites, enzyme-linked immunosorbent assay (ELISA) detection of antigen, rapid Quik Chek, and polymerase chain reaction (PCR) detection of DNA. In order to diagnose Giardia spp. properly, a combination of tests are often required. Microscopy has been historically the most commonly used but has limited diagnostic use and is no longer recommended as a reliable method of diagnosing giardiasis. While qualified microscopists in only one stool specimen will reduce the inaccuracy of Giardia detection (56). Yet microscopy does not differentiate between two Giardia human infecting large genotypic assemblages ( $A$ and $B$ ). On the other hand antigen detection technology has improved and is easy to use to resolve some of the drawbacks of stool microscopy. Only 35 Giardia cysts were detected by microscopy in a recent study of 157 stool samples compared with 127 showed positive results for Giardia cyst-specific antigen by Giardia II ELISA package (Techlab, Blacksburg) (57). Similarly, a cohort study of 229 Bangladeshi children found that ELISA's antigen detection test was 100\% sensitive and accurate compared to $94.5 \%$ and $99.8 \%$ respectively for microscopy (58). Currently there are rapid antigen test for the diagnosis of giardiasis in stool sample are available. Juliana et al. compare three rapid antigen tests for Giardia using ELISA as a reference standard in this issue, the Giardia Quik Chek (Techlab) had $100 \%$ and $98.8 \%$ sensitivity and specificity respectively (59). This sample panel included both symptomatic and asymptomatic stool specimens from 117 Bangladeshi children. Additionally in comparison with real-time PCR as a reference standard Giardia Quik Chek shown sensitivity and specificity $78 \%$ and $100 \%$ respectively. Stool PCR is extremely sensitive and it is considered as a gold standard for diagnosis of giardiasis. The use in routine diagnostic laboratories of these molecular diagnostic tests such as real-time PCR is still limited.

\section{Discussion And Perspective}

This systematic review observed the most common reported health consequences for Giardia infections in Bangladesh based on quality literature search. Although the search strategy accepted only 17 full 
articles out of 187 papers these were quality warranting inclusion.

What decides whether a flagellated Giardia spp. protozoan is a harmless parasite or a damaging pathogen or not? The true clinical adverse effects of pediatric giardiasis are not clear, but current prospective studies have reported a high burden of giardiasis diarrhea and subclinical infections are associated with child growth retardation. Recent worldwide laboratory work to understand the relationship between Giardia infection and health issues indicates new research lines.

In many regions of the world including Bangladesh, giardiasis is considered the most frequently reported intestinal parasite protozoan across humans, but giardiasis remains a neglected disease. Long-term Giardia infection can result in complications, such as damage to the cells that line the intestines. Morbidities associated with Giardia have been gradually established over the past decades, including extra-intestinal symptoms and long-term consequences (60-62). A cross-sectional study examined the role of giardiasis in the development of growth and psychomotor, suggesting an adverse impact of Giardia intestinalis infection (63). Another study in rural Malaysia reveals Giardia infection has significantly associated with the weight of children (64). Many epidemiological studies showed that childhood growth retardation has been associated with giardiasis in developing countries (65-69). Recent data from Bangladeshi children found similar results indicating that infection with Giardia could be a potential barrier to children's development $(32-34,40)$. The prospective MAL-ED birth-cohort study give us a special opportunity to explore the relationship among giardiasis and child growth (35).

The worst symptoms of Giardia infection are associated with damage to the absorptive small intestine mucosa, along with an impaired intestinal immunity that contributes to chronic infection. Recently published data from children in Bangladesh suggested a correlation between giardiasis and increased the risk of intestinal permeability as well as an immune defect $(35,37,38)$. Although an observation by Scott et al. showed that small intestinal gut permeability increased of Giardia infected mice without any morphological damage to the intestinal mucosa, which is independent of T-cell and is secondary to reorganization of cytoskeletal F-actin and tight-junction Z0-1 protein (70). To understand the relationship among infection and intestinal permeability, more studies are needed in children with Giardia infection.

Diarrheal diseases is a crucial problem in public health that particularly affects children in Bangladesh (71). The bidirectional correlation between malnutrition and diarrheal mortality has been known for decades $(72,73)$. Enteric infections such as Giardia spp. cause a significant proportion of global malnutrition. (73). Although more studies are needed to determine the actual health effects of giardiasis. Recently, an increased number of Giardia spp. has been identified in Bangladesh, especially in children.

This systematic review has few limitations including the number of articles observed. As we followed a strict number of inclusion criteria for this review, resulted a large number of articles removed from the consideration, because of their reports were incomplete or inappropriate. Several articles demonstrated diarrheal related health problems in generally without analysis of etiological agent individually especially for Giardia spp. were also excluded. 


\section{Conclusions}

Giardia spp. is one of the most frequent flagellated protozoan parasite infecting human in Bangladesh especially in children. Recent studies suggested that giardiasis adverse health effects are acute diarrhea, poor child growth and increased intestinal permeability, which can contribute many systemic disorders. However, prevention remains difficult, sufficient awareness should be given for preventing Giardia infection in children in Bangladesh to improve their health status.

\section{Declarations}

\section{List of abbreviations:}

WHO- $\quad$ World Health Organization

PRISMA- $\quad$ Preferred Reporting Items for Systematic Reviews and Meta-Analyses

LMIC- $\quad$ Low and Middle-Income Countries

LAZ- $\quad$ Length-for-age Z score

WAZ- Weight-for-age Z score

GSIgM- Giardia-specific Immunoglobulin M

MAL-ED- $\quad$ Malnutrition and Enteric Disease

AGP- $\quad$ Acid Glycoprotein

MPO- $\quad$ Myeloperoxidase

ELISA- $\quad$ Enzyme Linked Immunosorbent Assay

PCR- $\quad$ Polymerase Chain Reaction

AAT- $\quad$ Alpha1 Anti Trypsin

EED- Environmental Enteric Dysfunction

Ethics approval and consent to participate:

Not Applicable

\section{Consent for publication:}

Not Applicable 
Availability of data and materials:

Not Applicable

Competing interests:

The authors declare they have no competing interests.

\section{Funding:}

Not Applicable

\section{Authors' contributions:}

$\mathrm{BH}$ conceived the study. $\mathrm{BH}$ and $\mathrm{HR}$ wrote the analysis plan. $\mathrm{BH}$ conducted the literature review, analysis and wrote the first draft of manuscript. HR, SM and AS reviewed the first draft manuscript and suggested additional analyses. $\mathrm{ZN}$ and $\mathrm{MK}$ reviewed the final draft manuscript and provided critical comments. $\mathrm{BH}$ finalized the manuscript which was subsequently approved by all authors.

\section{Acknowledgements:}

Emerging Infections and Parasitology Laboratory department of Infectious Diseases Division of the International Centre for Diarrheal Disease Research, Bangladesh; Dhaka, Bangladesh.

\section{Authors details:}

${ }^{1}$ Rashidul Haque

Senior scientist and head, Emerging infections and parasitology laboratory, IDD, icddr,b

${ }^{1}$ Biplob Hossain

Research officer, Emerging infections and parasitology laboratory, IDD, icddr,b

${ }^{1}$ Humaira Rashid

PhD Student and Research Fellow, Emerging infections and parasitology laboratory, IDD, icddr,b

${ }^{1}$ Zannatun Noor

Deputy Project Coordinator, Emerging infections and parasitology laboratory, IDD, icddr,b

${ }^{1}$ Mamun Kabir

Research Investigator, Enteric and Respiratory Infections Department, IDD, icddr,b 
${ }^{1}$ Abdullah Siddique

Senior Research officer, Emerging infections and parasitology laboratory, IDD, icddr,b

${ }^{2}$ Sohag Miah

Student fellow, Shahjalal University of Science \& Technology; Sylhet-3114, Bangladesh

\section{References}

1. Savioli L, Smith H, Thompson A. Giardia and Cryptosporidium join the 'Neglected Diseases Initiative'. Trends Parasitol. 2006;22(5):203-8.

2. Younas $M$, Shah $S$, Talaat $A$. Frequency of Giardia lamblia infection in children with recurrent abdominal pain. J Pak Med Assoc. 2008;58(4):171-4.

3. Feng Y, Xiao L. Zoonotic potential and molecular epidemiology of Giardia species and giardiasis. Clin Microbiol Rev. 2011;24(1):110-40.

4. Rogawski ET, Bartelt LA, Platts-Mills JA, Seidman JC, Samie A, Havt A, et al. Determinants and Impact of Giardia Infection in the First 2 Years of Life in the MAL-ED Birth Cohort. J Pediatric Infect Dis Soc. 2017;6(2):153-60.

5. Ali SA, Hill DR. Giardia intestinalis. Current opinion in infectious diseases. 2003;16(5):453-60.

6. Nygard K, Schimmer B, Sobstad O, Walde A, Tveit I, Langeland N, et al. A large community outbreak of waterborne giardiasis-delayed detection in a non-endemic urban area. BMC public health. 2006;6:141.

7. Gillespie SH, Pearson RD. Principles and practice of clinical parasitology: Wiley Online Library; 2001.

8. World Health Organization. The World health report: 1996: fighting disease, fostering development. World Health Organization; 1996.

9. Prevention WECo, Infections ColP. Prevention and control of intestinal parasitic infections: report of a WHO expert committee: World Health Organization; 1987.

10. Berkman DS, Lescano AG, Gilman RH, Lopez SL, Black MM. Effects of stunting, diarrhoeal disease, and parasitic infection during infancy on cognition in late childhood: a follow-up study. The Lancet. 2002;359(9306):564-71.

11. Thompson RC, Reynoldson JA, Mendis AH. Giardia and giardiasis. Advances in parasitology. 1993;32:71-160.

12. Dalton C, Goater AD, Pethig R, Smith HV. Viability of Giardia intestinalis cysts and viability and sporulation state of Cyclospora cayetanensis oocysts determined by electrorotation. Appl Environ Microbiol. 2001;67(2):586-90.

13. Gendrel D, Treluyer J, Richard-Lenoble D. Parasitic diarrhea in normal and malnourished children. Fundamental \& clinical pharmacology. 2003;17(2):189-97. 
14. Al-Mekhlafi HM, Surin J, Sallam AA, Abdullah AW, Mahdy MA. Giardiasis and poor vitamin A status among aboriginal school children in rural Malaysia. The American journal of tropical medicine and hygiene. 2010;83(3):523-7.

15. UNICEF. Progress for children: a report card on nutrition: Unicef; 2006.

16. Nutrition I. The achievable imperative for global progress New York. NY United Nations Children's Fund: New York, NY, USA. 2013.

17. Esch KJ, Petersen CA. Transmission and epidemiology of zoonotic protozoal diseases of companion animals. Clinical microbiology reviews. 2013;26(1):58-85.

18. Feng Y, Xiao L. Zoonotic potential and molecular epidemiology of Giardia species and giardiasis. Clinical microbiology reviews. 2011;24(1):110-40.

19. Liu L, Oza S, Hogan D, Chu Y, Perin J, Zhu J, et al. Global, regional, and national causes of under-5 mortality in 2000-15: an updated systematic analysis with implications for the Sustainable Development Goals. The Lancet. 2016;388(10063):3027-35.

20. Petri Jr WA, Haque R, Mondal D, Karim A, Molla IH, Rahim A, et al. Prospective case-control study of the association between common enteric protozoal parasites and diarrhea in Bangladesh. Clinical Infectious Diseases. 2009;48(9):1191-7.

21. Haque R, Roy S, Kabir M, Stroup SE, Mondal D, Houpt ER. Giardia assemblage A infection and diarrhea in Bangladesh. The Journal of infectious diseases. 2005;192(12):2171-3.

22. Kabir M, Ahmed E, Hossain B, Alam M, Ahmed S, Taniuchi M, et al. Giardia/Cryptosporidium QUIK CHEK Assay Is More Specific Than Quantitative Polymerase Chain Reaction for Rapid Point-of-care Diagnosis of Cryptosporidiosis in Infants in Bangladesh. Clinical Infectious Diseases. 2018;67(12):1897-903.

23. Cotton JA, Beatty JK, Buret AG. Host parasite interactions and pathophysiology in Giardia infections. International journal for parasitology. 2011;41(9):925-33.

24. Scott KG-E, Linda C, Buret AG. Role of CD8+ and CD4+ T lymphocytes in jejunal mucosal injury during murine giardiasis. Infection and immunity. 2004;72(6):3536-42.

25. Buret A, Gall D, Olson M. Growth, activities of enzymes in the small intestine, and ultrastructure of microvillous border in gerbils infected withGiardia duodenalis. Parasitology research. 1991;77(2):109-14.

26. Buret A. Pathophysiology of enteric infections with Giardia duodenalis. EDP Sciences; 2008.

27. Chin AC, Teoh DA, Scott KG-E, Meddings JB, Macnaughton WK, Buret AG. Strain-dependent induction of enterocyte apoptosis by Giardia lamblia disrupts epithelial barrier function in a caspase-3dependent manner. Infection and immunity. 2002;70(7):3673-80.

28. Troeger H, Epple H-J, Schneider T, Wahnschaffe U, Ullrich R, Burchard G-D, et al. Effect of chronic Giardia lamblia infection on epithelial transport and barrier function in human duodenum. Gut. 2007;56(3):328-35. 
29. Koot BG, ten Kate FJ, Juffrie M, Rosalina I, Taminiau JJ, Benninga MA. Does Giardia lamblia cause villous atrophy in children?: A retrospective cohort study of the histological abnormalities in giardiasis. Journal of pediatric gastroenterology and nutrition. 2009;49(3):304-8.

30. Ankarklev J, Jerlström-Hultqvist J, Ringqvist E, Troell K, Svärd SG. Behind the smile: cell biology and disease mechanisms of Giardia species. Nature Reviews Microbiology. 2010;8(6):413.

31. Buret AG, Bhargava A. Modulatory mechanisms of enterocyte apoptosis by viral, bacterial and parasitic pathogens. Critical reviews in microbiology. 2014;40(1):1-17.

32. Rogawsk ET, Liu J, Platts-Mill JA, Kabir F, Lertsethtakarn P, Kalam A, et al. Use of quantitative molecular diagnostic methods to investigate the effect of enteropathogen infections on linear growth in children in low-resource settings: longitudinal analysis of results from the MAL-ED cohort study. Lancet Global Health. 2018;109(18):30351.

33. Platts-Mills JA, Taniuchi M, Uddin MJ, Sobuz SU, Mahfuz M, Gaffar SA, et al. Association between enteropathogens and malnutrition in children aged 6-23 mo in Bangladesh: a case-control study. The American journal of clinical nutrition. 2017;105(5):1132-8.

34. Donowitz JR, Alam M, Kabir M, Ma JZ, Nazib F, Platts-Mills JA, et al. A prospective longitudinal cohort to investigate the effects of early life giardiasis on growth and all cause diarrhea. Clinical Infectious Diseases. 2016;63(6):792-7.

35. Rogawski ET, Bartelt LA, Platts-Mills JA, Seidman JC, Samie A, Havt A, et al. Determinants and impact of Giardia infection in the first 2 years of life in the MAL-ED birth cohort. Journal of the Pediatric Infectious Diseases Society. 2017;6(2):153-60.

36. Goto R, Mascie-Taylor CN, Lunn PG. Impact of intestinal permeability, inflammation status and parasitic infections on infant growth faltering in rural Bangladesh. British journal of nutrition. 2009;101(10):1509-16.

37. Fahim SM, Das S, Gazi MA, Mahfuz M, Ahmed T. Association of intestinal pathogens with faecal markers of environmental enteric dysfunction among slum-dwelling children in the first 2 years of life in Bangladesh. Tropical Medicine \& International Health. 2018;23(11):1242-50.

38. Mondal D, Minak J, Alam M, Liu Y, Dai J, Korpe P, et al. Contribution of enteric infection, altered intestinal barrier function, and maternal malnutrition to infant malnutrition in Bangladesh. Clinical Infectious Diseases. 2011;54(2):185-92.

39. Mondal D, Haque R, Sack RB, Kirkpatrick BD, Petri Jr WA. Attribution of malnutrition to cause-specific diarrheal illness: evidence from a prospective study of preschool children in Mirpur, Dhaka, Bangladesh. The American journal of tropical medicine and hygiene. 2009;80(5):824-6.

40. Lutfun Nahar, Sagarmay Barua, Golam Firoz et al. Prevalence of Parasitic Infestation among Under-5 Children of Low Socio-economic Status. 1999

41. Hanevik K, Kristoffersen E, Svard S, Bruserud O, Ringqvist E, Sørnes S, et al. Human cellular immune response against Giardia lamblia 5 years after acute giardiasis. Journal of Infectious Diseases. 2011;204(11):1779-86. 
42. Bartelt LA, Roche J, Kolling G, Bolick D, Noronha F, Naylor C, et al. Persistent G. lamblia impairs growth in a murine malnutrition model. The Journal of clinical investigation. 2013;123(6):2672-84.

43. Müller N, Von Allmen N. Recent insights into the mucosal reactions associated with Giardia lamblia infections. International journal for parasitology. 2005;35(13):1339-47.

44. Buret A, Scott K, Chin A. Giardiasis: pathophysiology and pathogenesis. Giardia, the cosmopolitan parasite. 2002:109-1126.

45. Gascón J. Epidemiology, etiology and pathophysiology of traveler's diarrhea. Digestion. 2006;73(Suppl. 1):102-8.

46. Buret A, Hardin JA, Olson ME, Gall DG. Pathophysiology of small intestinal malabsorption in gerbils infected with Giardia lamblia. Gastroenterology. 1992;103(2):506-13.

47. Cevallos A-M, Carnaby S, James M, Farthing MJ. Small intestinal injury in a neonatal rat model of giardiasis is strain dependent. Gastroenterology. 1995;109(3):766-73.

48. Belosevic M, Faubert G, MacLean J. Disaccharidase activity in the small intestine of gerbils (Meriones unguiculatus) during primary and challenge infections with Giardia lamblia. Gut. 1989;30(9):1213-9.

49. Northrop-Clewes CA, Rousham EK, Mascie-Taylor CN, Lunn PG. Anthelmintic treatment of rural Bangladeshi children: effect on host physiology, growth, and biochemical status. The American journal of clinical nutrition. 2001;73(1):53-60.

50. Global, regional, and national incidence, prevalence, and years lived with disability for 310 diseases and injuries, 1990-2015: a systematic analysis for the Global Burden of Disease Study 2015. Lancet (London, England). 2016;388(10053):1545-602.

51. Ahmed T, Hossain M, Mahfuz M, Choudhury N, Ahmed S. Imperatives for reducing child stunting in Bangladesh. Maternal \& child nutrition. 2016;12(Suppl Suppl 1):242.

52. Baqui AH, Yunus M, Zaman K, Mitra A, Hossain K. Surveillance of patients attending a rural diarrhoea treatment centre in Bangladesh. Tropical and geographical medicine. 1991;43(1-2):17-22.

53. Hossain MA, Albert MJ, Hasan KZ. Epidemiology of shigellosis in Teknaf, a coastal area of Bangladesh: a 10-year survey. Epidemiology \& Infection. 1990;105(1):41-9.

54. Oberle MW, Merson MH, Islam MS, Rahman AM, Huber DH, Curlin G. Diarrhoeal Disease in Bangladesh Epidemiology, Mortality Averted and Costs at a Rural Treatment Centre. International journal of epidemiology. 1980;9(4):341-8.

55. Haque R, Mondal D, Kirkpatrick BD, Akther S, Farr BM, Sack RB, et al. Epidemiologic and clinical characteristics of acute diarrhea with emphasis on Entamoeba histolytica infections in preschool children in an urban slum of Dhaka, Bangladesh. The American journal of tropical medicine and hygiene. 2003;69(4):398-405.

56. Johnston SP, Ballard MM, Beach MJ, Causer L, Wilkins PP. Evaluation of three commercial assays for detection of Giardia and Cryptosporidium organisms in fecal specimens. Journal of clinical microbiology. 2003;41(2):623-6. 
57. Ahmed T, Khanum H, Barua P, Arju T, Uddin MS, Haque R. Detection of Giardia lamblia in children by microscopy, ELISA and real time PCR assay. Dhaka University Journal of Biological Sciences. 2014;23(2):197-204.

58. Goldin AJ, Hall A, Sarker RN, Warhurst DC, Miles MA. Diagnosis of Giardia duodenalis infection in Bangladeshi infants: faecal antigen capture ELISA. Transactions of the Royal Society of Tropical Medicine and Hygiene. 1993;87(4):428-32.

59. Minak J, Kabir M, Mahmud I, Liu Y, Liu L, Haque R, et al. Evaluation of rapid antigen point-of-care tests for detection of Giardia and Cryptosporidium species in human fecal specimens. Journal of clinical microbiology. 2012;50(1):154-6.

60. Cantey PT, Roy S, Lee B, Cronquist A, Smith K, Liang J, et al. Study of nonoutbreak giardiasis: novel findings and implications for research. The American journal of medicine. 2011;124(12):1175. e1-. e8.

61. Halliez MC, Buret AG. Extra-intestinal and long term consequences of Giardia duodenalis infections. World journal of gastroenterology: WJG. 2013;19(47):8974.

62. Almirall P, Núñez FA, Bello J, González OM, Fernández R, Escobedo AA. Abdominal pain and asthenia as common clinical features in hospitalized children for giardiasis. Acta tropica. 2013;127(3):212-5.

63. Simsek Z, Zeyrek FY, Kurcer M. Effect of Giardia infection on growth and psychomotor development of children aged 0-5 years. Journal of Tropical Pediatrics. 2004;50(2):90-3.

64. Al-Mekhlafi HM, Al-Maktari MT, Jani R, Ahmed A, Anuar TS, Moktar N, et al. Burden of Giardia duodenalis infection and its adverse effects on growth of schoolchildren in rural Malaysia. PLoS neglected tropical diseases. 2013;7(10):e2516.

65. Farthing MJ, Mata L, Urrutia JJ, Kronmal RA. Natural history of Giardia infection of infants and children in rural Guatemala and its impact on physical growth. The American journal of clinical nutrition. 1986;43(3):395-405.

66. Cole TJ, Parkin J. Infection and its effect on the growth of young children: a comparison of The Gambia and Uganda. Transactions of the Royal Society of Tropical Medicine and Hygiene. 1977;71(3):196-8.

67. Fraser D, Bilenko N, Deckelbaum RJ, Dagan R, El-On J, Naggan L. Giardia lamblia carriage in Israeli Bedouin infants: risk factors and consequences. Clinical infectious diseases. 2000;30(3):419-24.

68. Gupta S, Srivastava G. Drug therapy for giardia infestation. Indian pediatrics. 1978;15(8):687-9.

69. Prado MdS, Cairncross S, Strina A, Barreto ML, Oliveira-Assis A, Rego S. Asymptomatic giardiasis and growth in young children; a longitudinal study in Salvador, Brazil. Parasitology. 2005;131(1):516.

70. Scott KGE, Meddings JB, Kirk DR, Lees-Miller SP, Buret AG. Intestinal infection with Giardia spp. reduces epithelial barrier function in a myosin light chain kinase-dependent fashion. Gastroenterology. 2002;123(4):1179-90.

71. Kosek M, Bern C, Guerrant RL. The global burden of diarrhoeal disease, as estimated from studies published between 1992 and 2000. Bulletin of the world health organization. 2003;81:197-204. 
72. Roy S, Buis M, Weersma R, Khatun W, Chowdhury S, Begum A, et al. Risk factors of mortality in severely-malnourished children hospitalized with diarrhoea. Journal of health, population, and nutrition. 2011;29(3):229.

73. Brown KH. Diarrhea and malnutrition. The Journal of nutrition. 2003;133(1):328S-32S.

\section{Figures}

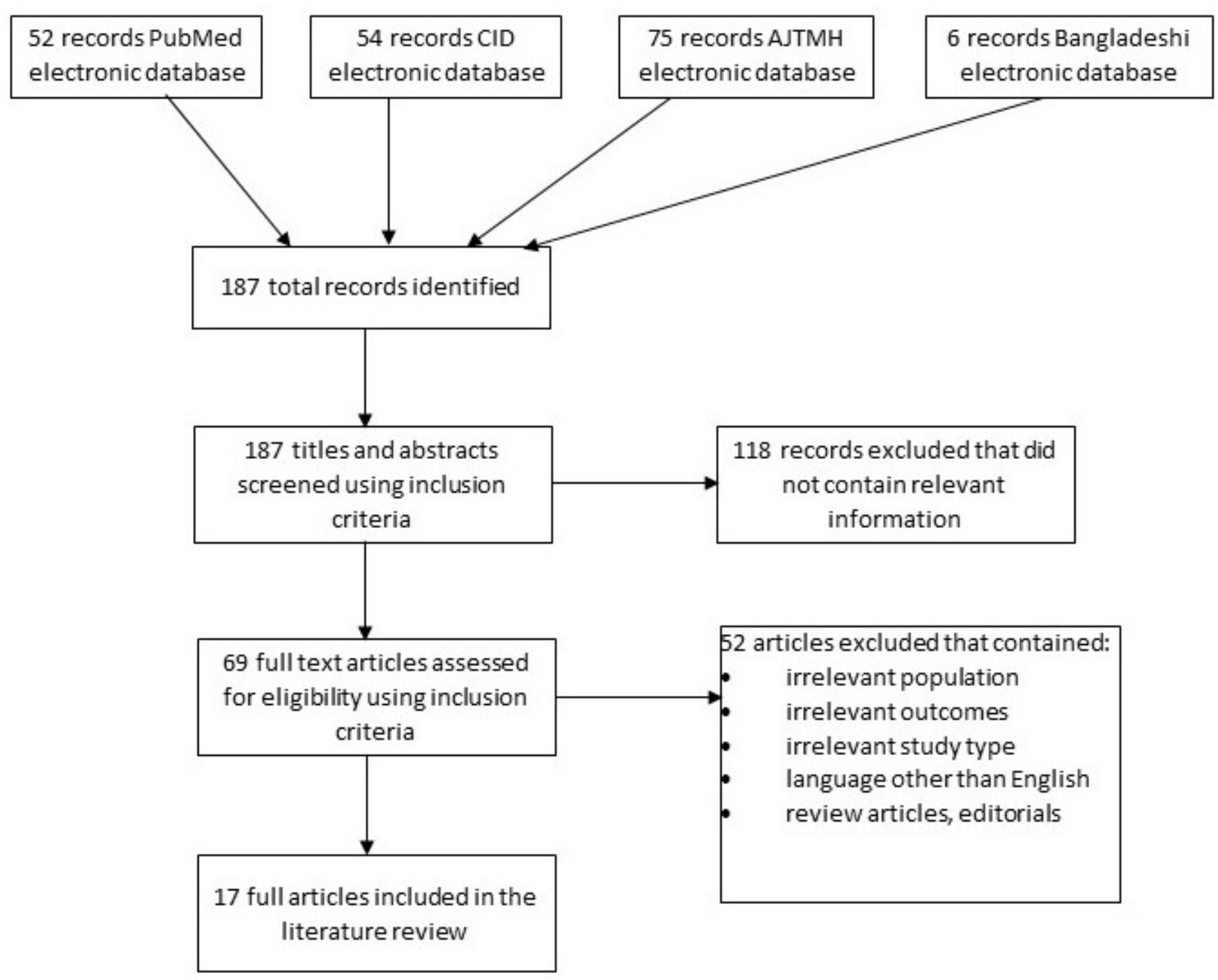

\section{Figure 1}

Flow diagram for systematic review: The PRISMA flow diagram for the systematic review outlining the search for the database, the number of abstracts reviewed and the full texts included. 


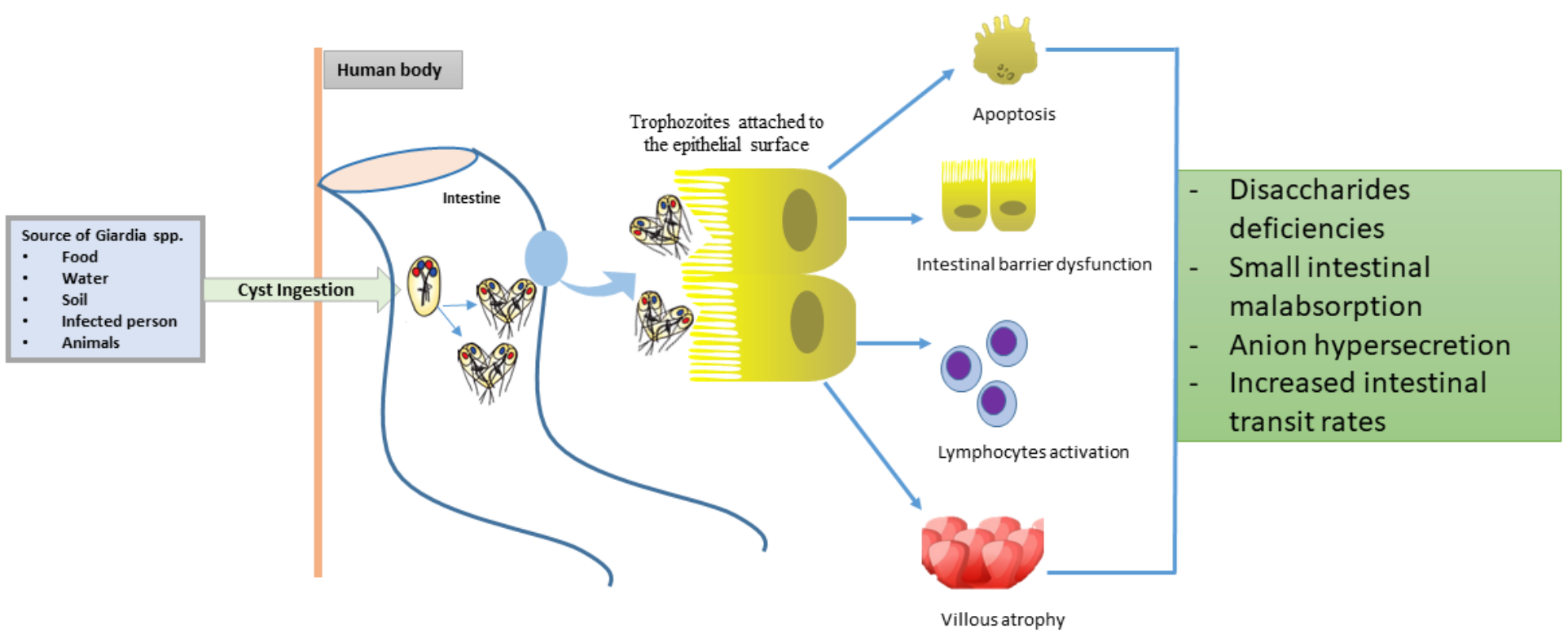

Figure 2

Clinical features and manifestation of Giardia spp. infection

\section{Supplementary Files}

This is a list of supplementary files associated with this preprint. Click to download.

- PRISMAchecklist.doc 